\title{
Percepção de agricultores familiares sobre suas condições de saúde e do ambiente
}

\author{
Pâmela Scussel* \\ Amanda Fabres Oliveira Radunz** \\ Maria Assunta Busato***
}

\section{INTRODUÇÃO}

Definido pela Lei 11.326/2006, agricultor familiar é aquele que trabalha no meio rural, não tem área maior do que quatro módulos fiscais ${ }^{1}$, a renda principal é resultante da produção agrícola da propriedade e utiliza predominantemente mão-de-obra dos membros da própria família para desenvolver o trabalho no estabelecimento, cenário comum na região Oeste do estado de Santa Catarina. Para além desta tipificação, é mister sinalizar que a agricultura familiar é categoria social presente na história brasileira muito antes de sua definição legal. Schneider e Niederle (2008) destacam que para compreensão teórica e conceitual, há necessidade de distinguir campesinato e agricultura familiar.

[...] Embora mantenham semelhanças entre si, como a propriedade de um pequeno lote de terra, o uso predominante do trabalho da família na execução das tarefas produtivas, o acesso à terra mediante a herança, a manutenção dos vínculos sociais assentados em relações de parentesco, entre outras; o traço fundamental que distingue os agricultores familiares dos camponeses assenta-se no caráter dos vínculos mercantis e das relações sociais que estabelecem à medida

\footnotetext{
* Graduada em Nutrição, pela Universidade Comunitária da Região de Chapecó (UNHOCHAPECÓ). E-mail: s.pamela354@gmail.com

** Doutoranda do Programa de Pós-Graduação em Ciências da Saúde, na Universidade Comunitária da Região de Chapecó (UNOCHAPECÓ). E-mail: amafaol@yahoo.com.br

*** Doutora em Biologia pela Universidade de Barcelona, Espanha. Master em Enfermidades Tropicais pela Universidade de Valência, Espanha. Docente da Universidade Comunitária da Região de Chapecó (UNOCHAPECÓ). E-mail: assunta@unochapeco.edu.br
} 
que se intensifica e se torna mais complexa a sua inserção na divisão social do trabalho. Ou seja, é o maior envolvimento social, econômico e mercantil que torna o agricultor familiar, ao mesmo tempo, mais integrado e mais dependente em relação à sociedade que lhe engloba. (Schneider e Niederle, 2008, p. 994)

Assim, há que se ressaltar que o conceito de agricultura familiar permanece na ordem do dia, haja vista as diferentes abordagens. Mesmo a tipificação legal supramencionada encontra entraves e pontos passíveis de controvérsia. Nesse sentido, observa-se que, por exemplo em casos de famílias que contem com dois ou mais indivíduos aposentados e que a renda oriunda da atividade agrícola seja menor que a somatória dos valores percebidos com as aposentadorias, essas não são consideradas de agricultura familiar. Isto é, as condições culturais, sociais, históricas, são - neste exemplo - desconsideradas. Todavia, mesmo diante de tal cenário, observa-se, a partir dos dados do Censo Agropecuário realizado em 2006 pelo Instituto Brasileiro de Geografia e Estatística (IBGE), que 84,36\% dos estabelecimentos agropecuários brasileiros são de agricultores familiares (SCHNEIDER; NIERDELE, 2008). Estes estabelecimentos produzem cerca de $70 \%$ dos alimentos consumidos no Brasil (MDA, 2017) e empregam 74,38\% dos trabalhadores no campo, o que representa importante setor de ocupação da mãode-obra trabalhadora no Brasil, mesmo após o êxodo rural observado após a década de 1970 (SCHNEIDER; NIERDELE, 2008).

Ainda no contexto abordado ressalta-se os pacotes tecnológicos de produção agrícola, os quais foram introduzidos a partir da revolução verde, e pautaram-se na utilização intensiva de insumos e tecnologias, que, por sua vez, convergiram para problemas ambientais e sociais (MILLER, 2008). A revolução verde foi responsável por produzir alterações nas relações de trabalho da agricultura, bem como, impôs dificuldades e desafios para os agricultores (SANTOS et al., 2014), conduzindo a homogeneização dos sistemas de agrários, sem considerar as características intrínsecas a cada realidade local (RADUNZ; RADUNZ, 2017). Desta forma, a revolução verde influenciou na autonomia e na maneira como os agricultores familiares participam do mercado. A dependência destes agentes em relação ao manejo e, mesmo a continuidade da produção, aprofundou-se. Por outra via, a emergência de sistemas de produção diferentes daquele apresentado pela Revolução Verde têm se destacando recentemente. Para Radunz e Radunz (2017) a agricultura familiar apresenta condições de aliar a produção econômica à preservação ambiental ao desenvolver atividades de mercado diferenciadas, como a prática de agriculturas alternativas. Salienta-se a adoção da visão sistêmica no processo produtivo, considerando as multidimensões da sustentabilidade.

Neste cenário, desponta o cultivo agroecológico como uma alternativa viável, a qual permite ao agricultor maior independência frente ao processo produtivo, além da possibilidade de agregar valor aos produtos cultivados na unidade familiar e comercializar a sua produção diretamente ao consumidor final 
(RADUNZ; RADUNZ, 2017). Para Meirelles (2004), a agroecologia apresentase como uma resposta socioambiental aos problemas provocados pela revolução verde, pois além de propor a prática de uma agricultura sustentável é capaz de contribuir para a segurança alimentar dos núcleos familiares ao produzir alimentos saudáveis e praticar a diversificação na matriz produtiva.

Assume-se ainda que uma característica da agricultura familiar é a forte relação que agricultores possuem com o meio ambiente, percebendo-se cuidados diferenciados no modo de produção, conforme citam Borges et al. (2016). A prioridade da agricultura familiar é a relação que os agricultores têm com o ambiente que estão inseridos, pois é a fonte de subsistência de toda a unidade familiar, e sustenta o convívio com a comunidade. Se o ambiente é agredido as necessidades daquela comunidade não serão atendidas. Desta maneira, ressalta-se que esta categoria social, desempenha importante papel para o Desenvolvimento Rural Sustentável. Este último entendido numa perspectiva de co-evolução das pessoas com a natureza, considerando a equidade social e a cultura como fatores fundamentais, figurando entre seus princípios norteadores a agroecologia (OLIVEIRA; JAIME, 2016).

Outro aspecto relevante à agricultura familiar é a conscientização por parte dos agricultores da relação existente entre alimentação e saúde, cuidado que fica evidente quando se fala do uso de agrotóxicos. Para Radunz e Radunz (2017), ao pesquisarem os aspectos relativos ao cultivo, comercialização e segurança alimentar com agricultores familiares de base ecológica que comercializam seus produtos na feira agroecológica da Associação Regional de Produtores Agroecologistas da Região Sul (ARPA-SUL) em Pelotas/RS, identificaram que a principal motivação, que levou os agricultores familiares a abandonar ou substituir o cultivo convencional por cultivos agroecológicos nas propriedades, envolveu problemas de saúde que estes apresentaram. De acordo com os entrevistados naquela pesquisa, tais problemas provenientes de práticas associadas ao cultivo convencional, causados pela utilização massiva de agrotóxicos e poluição dos recursos naturais. Nesse sentido, a escolha por determinado sistema de produção implica em diversos e diferentes fatores, que envolvem aspectos relacionados desde a produtividade à condições de saúde e ambiente. Segundo Scopinho (2010), os agricultores têm uma percepção, sobre o processo de saúde-doença, extremamente particular, relacionada às suas próprias condições de vida, tendo como parâmetros a ideia de estar ou não apto ao trabalho, se utiliza agrotóxicos ou não, entre outros. Nesse sentido, é importante conhecer a percepção dos agricultores familiares sobre o ambiente onde estão inseridos e de onde tiram a renda da família, bem como sua autopercepção de saúde e o manejo da terra. Considerando este contexto, este estudo se propôs a compreender a percepção de agricultores familiares do município de Seara-SC, sobre suas condições de saúde e as do ambiente. 


\section{DESENVOLVIMENTO METODOLÓGICO}

O estudo envolveu agricultores familiares do município de Seara, situado no oeste catarinense, cuja população é de 16.936 habitantes (IBGE, 2010). A pesquisa é qualitativa, uma vez foi realizada com indivíduos com diferentes concepções, modo de ser, pensar e agir que não são os mesmos e nem deveriam, tal como salienta Minayo (2016, p. 21) que "[...] a pesquisa qualitativa responde a questões muito particulares. Ela se ocupa com um nível de realidade que não pode ou não deveria ser quantificada".

Como método, foi utilizada a amostragem bola de neve (snow ball) que localiza e seleciona os participantes do estudo. Este tipo de amostragem utiliza cadeias de referência, ou seja, não é possível determinar quais participantes realmente irão participar da pesquisa, sendo uma forma de amostragem não probabilística (VINUTO, 2014).

Para a primeira fase foram levantadas informações junto às comunidades do interior do município para saber sobre agricultores familiares. Foi escolhido, aleatoriamente, uma família de agricultores familiares para iniciar a entrevista. A primeira família selecionada é chamada de "semente" a qual ajuda o pesquisador a iniciar seus contatos e formar o grupo a ser pesquisado" (VINUTO, 2014). Depois de realizado os primeiros contatos foi solicitado que as pessoas/famílias indicadas também fizessem a indicação de novos contatos com as características que se encaixassem nos parâmetros. As entrevistas foram cessadas quando foram obtidas as respostas para os objetivos do estudo.

Para a coleta de dados foi utilizado um roteiro semiestruturado com questões abertas e fechadas que deixaram os entrevistados expressarem sua percepção sobre ambiente onde está inserida sua propriedade e percepção das condições de saúde. O diálogo com as famílias ocorreu em suas residências, em horários pré-agendados, no período entre março e abril de 2018. Os resultados estão apresentados de forma descritiva observando os núcleos temáticos (MINAYO, 2016) manifestados nas entrevistas com os agricultores familiares. No diálogo com as famílias participaram, normalmente, o agricultor (pai), a agricultora (mãe) e, em algumas famílias, também os filhos maiores de 18 anos. O estudo envolveu 12 famílias de agricultores familiares que residem no município de Seara - SC.

$\mathrm{O}$ projeto que deu origem a esta pesquisa foi aprovado pelo Comitê de Ética em Pesquisa (CEP) da Universidade Comunitária da Região de Chapecó sob número 020634/2018.

\section{INFORMAÇÕES OBTIDAS E DISCUSSÃO}

Os agricultores familiares participantes deste estudo têm, em média, 22 anos de trabalho na agricultura. A maioria dos pais dessas famílias cursaram 
ensino fundamental incompleto, ao passo que os jovens, filhos de agricultores familiares, apresentam maior escolaridade. Dentre os jovens é recorrente a busca pelo ensino superior e na sequência o retorno residir/trabalhar nas propriedades. A permanência dos filhos nas propriedades e mesmo na atividade agrícola, observada nesta pesquisa, não reflete uma realidade majoritária em outros espaços. Acredita-se que tal posicionamento possa estar atrelado ao fato de todos os agricultores entrevistados desenvolverem sistemas de produção orgânicos, ou seja, o trabalho estar associado a uma perspectiva que contempla outros aspectos que não apenas o econômico.

Dentre as famílias entrevistadas, a maioria dos filhos ajudam nas atividades agrícolas e não pretendem mudar para a zona urbana. Tal realidade expressa-se inclusive entre aqueles que cursaram ensino superior. Essa perspectiva é evidenciada na fala dos entrevistados, em especial, um deles que mencionou "Uma filha faz faculdade, mas pretende permanecer no campo, mas a outra não tem interesse" (A6). Nota-se que as características culturais, sociais, religiosas e a qualidade de vida são aspectos que, dentre outros, contribuem para a decisão de residir na zona rural. A importância do vínculo e da sucessão nas propriedades foram igualmente observadas. Para uma das entrevistadas, esta continuidade está garantida: "Sempre ajudei nos afazeres da propriedade desde bem nova, e não pretendo sair daqui. Tenho interesse e pretendo continuar com os negócios da família" (A4). Depreende-se que esta relação diferencia-se da observada na maioria dos estudos sobre sucessão agrícola, uma vez que há processos de esvaziamento, envelhecimento e masculinização no rural. Kummer e Colognese (2013) discorrem sobre tais processos, sinalizando que "a reprodução da propriedade rural é, também, a reprodução do ambiente familiar e do tecido social rural, bem como a estrutura de todo setor agrícola" (p. 216). A participação dos filhos de agricultores familiares ocorre, portanto, por meio de diferentes vias, sejam essas desde a observação até o pleno desenvolvimento das atividades ao longo da vida. O "saber fazer" é ensinado e aprendido ao longo da vida, majoritariamente de maneira empírica.

Dentre os entrevistados outro importante elemento a ser analisado está vinculado à produção de alimentos e à segurança alimentar e nutricional. A produção para a comercialização e o autoconsumo nas propriedades com produção orgânica é situação bastante recorrente. E este é outro importante motivo que estimula a permanência dos jovens nas propriedades, uma vez que os benefícios oriundos de uma alimentação nutricionalmente equilibrada, em quantidade satisfatória e livre de agrotóxicos industrializados oportuniza melhores condições de saúde.

Caporal e Costabeber (2003) ao discorrerem sobre a segurança alimentar sinalizam:

A expressão segurança alimentar, como conceito orientador para políticas públicas, apareceu em 1974, durante a Conferência 
Mundial da Alimentação promovida pela FAO. Em 1996, a FAO estabelecia um conceito mais ambicioso, ao afirmar que se trata de assegurar o acesso aos alimentos para todos e a todo o momento, em quantidade e qualidade suficientes para garantir uma vida saudável e ativa. A partir do estabelecimento deste conceito, ficou mais patente a importância de uma agricultura que produza alimentos básicos (e não apenas commodities), com adequada qualidade biológica. Ademais, o conceito alerta para a necessidade de que a agricultura seja mais respeitosa com o meio ambiente, de modo a assegurar a conservação da base de recursos naturais indispensável para a produção ao longo do tempo (149).

A relação com o ambiente e a valorização de uma visão mais holística da produção fez com que a produção orgânica surgisse como alternativa viável à produção convencional. O interesse das famílias em permanecer no meio rural e dar continuidade às atividades agrícolas, especialmente na produção de alimentos isentos de produtos químicos industriais, obtendo daí seu sustento, ganhou novo fôlego. Ainda em relação ao uso de agrotóxicos, os entrevistados manifestam os problemas causados ao meio ambiente e à saúde:

Os agrotóxicos são extremamente prejudiciais ao meio ambiente, pois contaminam o solo, a água, o ar, afetam a biodiversidade, entre outras consequências. (A5)

Causa danos de forma direta, tanto para a saúde como para o ambiente, como podemos observar nas mídias a ligação de doenças com agrotóxicos vem aumentando. (A8)

O uso em massa de insumos agroindustriais foi motivado a partir da revolução verde, quando a difusão de novas tecnologias agrícolas auxiliou para o crescimento da produção. A maior produtividade, associada também à mecanização e, consequentemente dispensa de mão-de-obra impulsionou o aumento do êxodo rural. Juntamente a esse crescimento de produção e a modernização das tecnologias, vieram as preocupações recorrentes do uso intenso e desenvolvimento de adubos, agrotóxicos e alteração genética dos alimentos (OCTAVIANO, 2010). A preocupação com a saúde, seja diretamente da família ou dos consumidores foi um dos elementos suscitados como preponderantes na decisão em continuar exercendo atividades agrícolas. Ponto que serve de incentivo para esta continuidade da agricultura familiar encontra-se a importância de produzir alimentos livres de agrotóxicos e que, a priori, não possuam resíduos que afetem a vida (MOREIRA, 2013).

A Lei 10.831, aprovada em 23 de dezembro de 2003, dispõe sobre a produção orgânica, que foi criada com a principal finalidade de ofertar produtos saudáveis, que não possuam agrotóxicos e que estejam preservando a biodiversidade dos 
ecossistemas naturais e promovendo a utilização saudável do solo, da água e do ar, além de reciclar resíduos orgânicos, diminuindo a uma margem mínima o emprego de recursos não renováveis (BRASIL, 2003 apud ALVES, 2012, p. 23).

A diversificação da produção em propriedades com sistema de produção orgânica inclui produção de gado de corte, leite, suínos, laticínios, apicultura, meliponicultura, olericultura, legumes, plantas medicinais, cana-de-açúcar, geleias, frutas, plantas condimentares e aromáticas, e flores medicinais. Dentre as famílias entrevistadas foi identificado o consumo de tudo o que é produzido nas propriedades, principalmente hortaliças, legumes e frutas. Das doze famílias deste estudo, quatro possuem certificação de produção orgânica e de toda propriedade. Segundo Oliveira (2010), o fato de o produto orgânico ter uma certificação específica já o faz sobressair-se aos demais. Os produtos orgânicos certificados apresentam um selo ou impressão no rótulo aferindo que estes foram produzidos em conformidade as normas e práticas da agricultura orgânica. As demais famílias entrevistadas não possuem certificação, mas asseguram que a produção ocorre segundo o modelo orgânico. Sobre os fatores que limitam a produção orgânica os agricultores familiares entrevistados foram unânimes ao mencionar o alto custo para a produção e a falta de políticas públicas e governamentais para apoio ou subsídio de produção.

A preservação do solo é igualmente observada neste sistema de produção. $\mathrm{Na}$ perspectiva da produção orgânica de alimentos há um cuidado com o manuseio da terra, considerando a importância desta para a continuidade da atividade agrícola e, por conseguinte, das próximas gerações possam cultivar no mesmo solo, com condições de utiliza-lo para produção comercial.

No concernente à saúde, salienta-se que esta é intimamente relacionada à capacidade do agricultor familiar conseguir desempenhar o seu trabalho, atentando para sua alimentação e lazer. Observando estes itens que lhe são importantes chega-se à conclusão que a sua percepção de saúde está diretamente ligada a sua condição de saúde psicológica e a situação financeira (MINAYO; HARTZ; BUSS, 2000). Neste aspecto, os agricultores citam que cuidam da alimentação, dando prioridade a alimentos oriundos da propriedade. Quando indagados se alimentação pode influenciar na saúde, eles afirmaram:

Com certeza, pois os alimentos que ingerimos são espécie de "remédios preventivos", potencializando todas as formas de autocura de nosso corpo. (A2)

Se comermos alimentos saudáveis teremos uma vida melhor, sustento para desempenhar nossas atividades. (A7)

Considerando as manifestações dos agricultores sobre saúde e alimentação saudável, percebe-se que coincidem com o previsto no Guia Alimentar para 
a População Brasileira (BRASIL, 2014), o qual afirma que uma alimentação saudável é aquela que fornece todos os nutrientes necessários ao indivíduo, devendo ser respeitadas as condições sociais, econômicas, culturais, afetivas, pois a alimentação envolve este conjunto de fatores, além de conter alimentos variados, que respeitem a cultura, as tradições e os hábitos saudáveis.

$\mathrm{O}$ ambiente, tal como a alimentação, fora considerado pelos agricultores familiares entrevistados, de suma importância. A necessidade de um ambiente equilibrado, não poluído e com seus recursos naturais preservados foram alguns dos aspectos indicados durante as entrevistas. Tais elementos podem ser sublinhados na manifestação de alguns dos entrevistados.

Cuido diariamente da promoção da saúde de meu corpo/mente/espírito por meio dos alimentos que escolho, das atividades físicas que pratico, pela meditação e estudos a respeito do autoconhecimento. (A2).

Estamos buscando melhorias diariamente e levando o verde para aos arredores de casa, para cada vez ficar com ambiente mais saudável. Estamos com uma diversidade de árvores frutíferas não apenas para nosso consumo, mas para que os animais possam desfrutar também. (A8).

Explorando as opiniões dos entrevistados sobre o ambiente em que vivem, pode-se interligar com a definição de Silva (2004), que conceitua meio ambiente como, "[...] abrangente de toda a natureza, o artificial e original, bem como os bens culturais correlatos, compreendendo, portanto, o solo, a água, o ar, a flora, as belezas naturais, o patrimônio histórico, artístico, turístico, paisagístico e arquitetônico". Para um ambiente saudável, deve-se analisá-lo como um todo, todos os meios e fatores são importantes. Outro agricultor familiar evidenciou a preocupação da preservação do ambiente em que está inserido e o que faz para ter um ambiente saudável:

Temos vegetação que produz bom ar, água com proteção na nascente e alimentos orgânicos, isso ajuda para que o ambiente seja saudável, e preservado. Também buscamos manter um ambiente de convivência familiar o melhor possível. Também mantemos o melhor possível para que os animais e vegetais possam se reproduzir ao natural, com algumas intervenções. (A 12)

Observa-se que os agricultores demonstram preocupação com o meio ambiente. Afirmam que o lixo produzido na propriedade é separado em orgânico e inorgânico, sendo que o orgânico é utilizado em compostagem para adubação na produção de verduras e legumes. Já o lixo inorgânico é separado e, a cada dois meses recolhido pelo serviço público ou levado pelos agricultores para locais de descarte. Outra preocupação é em relação à água e sua qualidade. A maioria 
relatou retirar água direto da fonte, local que é isolado dos animais, em meio à mata verde com pouca possibilidade de ter contaminantes.

\section{CONSIDERAÇÕES FINAIS}

A opção pela produção orgânica, sem uso de agrotóxicos, é compreendida pelos agricultores como a melhor forma de cuidar da saúde, tanto da família como dos potenciais consumidores que adquirem seus produtos. Sob esse aspecto, os agricultores cuidam da alimentação dando prioridade ao consumo de alimentos produzidos na propriedade e, o excedente, é comercializado em feiras e casas coloniais.

Em relação à percepção sobre a qualidade do ambiente, observou-se grande preocupação com a preservação e sustentabilidade da atividade agrícola. A busca por alternativas de produção que assegurem a manutenção da propriedade é uma constante preocupação das famílias.

A continuidade da propriedade e o desenvolvimento da produção nos mesmos moldes atuais é de interesse dos filhos de algumas famílias de agricultores. Contudo, ainda é necessário a melhoria de políticas públicas para a efetivação desses jovens na atividade do campo da agricultura familiar orgânica.

\section{NOTA}

1 De acordo com a Embrapa, o módulo fiscal é uma unidade de medida determinada pelo INCRA (Instituto Nacional de Colonização e Reforma Agrária). Leva em consideração o tipo de exploração predominante no município e as demais explorações existentes e não predominantes, a renda obtida com o tipo de exploração dominante e o conceito de "propriedade familiar". O módulo fiscal varia conforme o município onde está a propriedade. No Brasil um módulo fiscal varia de 5 a 110 hectares

\section{REFERÊNCIAS}

ALVES, Alda Cristiane de Oliveira; SANTOS, André Luis de Sousa dos; AZEVEDO, Rose Mary Maduro Camboim de. Agricultura orgânica no Brasil: sua trajetória para a certificação compulsória. Revista Brasileira de Agroecologia, v. 7, n. 2. p. 19-27, set. 2012. BORGES, Anelise Miritz et al. Agricultura Familiar e a conservação da saúde humana e ambiental. Revista Brasileira de Enfermagem, Brasília, v. 69, n. 2, p. 326-334, mar/abr. 2016.

BRASIL. Ministério da Educação. Secretaria de Educação Básica. Guia Alimentar para a população brasileira. 2. ed. Brasília: Universidade de Brasília, 2014, 156 p.

CAPORAL, Francisco Roberto; COSTABEBER, José Antônio. Agroecologia e extensão rural. Contribuições para a Promoção do Desenvolvimento Rural sustentável. Porto Alegre/RS: EMATER/RS, 2003. Disponível em: <http://www.emater.tche.br/site/ arquivos_pdf/teses/agroecologia $\% 20 \mathrm{e} \% 20$ extensao $\% 20$ rural\%20 contribuicoes $\% 20$ para\%20a\%20promocao\%20de\%20desenvolvimento\%20rural\%20sustentavel.pdf > . Acesso em: 20 dez. 2019. 
IBGE. Instituto Brasileiro de Geografia e Estatística. Censo Demográfico 2010. Brasília: Rio de Janeiro, 2010. Disponível em: <http://www.censo2010.ibge.gov.br >. Acesso em: 28 ago. 2018.

KUMMER, Rodrigo; COLOGNESE, Silvio Antônio. Juventude rural no Brasil: entre ficar e partir. Tempo da Ciência, v. 20, n. 39, p. 201-220, 2013.

MEIRELLES, Laércio. Soberania alimentar, agroecologia e mercados locais. Revista Agriculturas: experiências em agroecologia, v. 1, p. 11-14, 2004.

MILlER JR, G. Tyler. Ciência Ambiental. Tradução de: All Tasks. Revisão técnica de: DELITTI, Welington Braz Carvalho. 11ª ed. São Paulo: Cengage Lerning, 2008.

MINAYO, Maria Cecília de Souza (Org.). Pesquisa social: teoria, método e criatividade. 24. ed. Petrópolis, RJ: Vozes, 2016.

MINAYO, Maria Cecília de Souza; HARTZ, Zulmira Maria de Araújo; BUSS, Paulo Marchiori. Qualidade de Vida e saúde: um debate necessário. Revista Ciência \& Saúde Coletiva. Rio de Janeiro, v. 5, n.1, p. 7-18, jan./jul. 2000.

MDA. Ministério do Desenvolvimento Agrário. Brasil: 70\% dos alimentos que vão à mesa dos brasileiros são da agricultura familiar. 2017. Disponível em: <http://www.mda. gov.br/sitemda/noticias/brasil-70-dos-alimentos-que-v\%C3\%A3o-\%C3\%A0-mesa-dosbrasileiros-s\%C3\%A3o-da-agricultura-familiar>. Acesso em: 10 dez. 2018.

MOREIRA, Magda Regina Santiago. Um olhar sobre a agricultura familiar, a saúde humana e o ambiente. Revista Ciência e Cultura. São Paulo, v. 65 n. 3, jul. 2013.

OCTAVIANO, Carolina. Muito além da tecnologia: os impactos da Revolução Verde. Revista ComCiência. Campinas, n. 120, 2010.

OLIVEIRA, Roberto Pedroso et al. Sistemas de Produção 20. Embrapa Clima Temperado. Pelotas, p. 296, 2010. ISSN 1806-9207. Disponível em: <https://www.infoteca.cnptia. embrapa.br/bitstream/doc/938021/1/15850.pdf> Acesso em: 22 nov. 2018.

OLIVEIRA, Nádia Rosana Fernandes de; JAIME, Patrícia Constante. O encontro entre o desenvolvimento rural sustentável e a promoção da saúde no Guia Alimentar para a População Brasileira. Revista Saúde \& Sociedade. São Paulo, v. 25 n. 4, p. 1108-1121, out./ dez. 2016.

RADUNZ, André Luiz; RADUNZ, Amanda Fabres Oliveira. Feira agroecológica da Arpasul, Pelotas, RS: produção, segurança alimentar e comercialização, um estudo de caso. Revista Espaço Acadêmico (UEM), v. 191, p. 1-20, 2017.

SCOPINHO, Rosemeri Aparecida. Condição de vida e saúde do trabalhador em assentamento rural. Revista Ciência \& Saúde Coletiva. Rio de Janeiro, v. 15, n. 1, p. 15751584, jun. 2010.

SCHNEIDER, Sérgio; NIEDERLE, Paulo André. In: Savanas: desafios e estratégias para o equilíbrio entre sociedade, agronegócio e recursos naturais Embrapa Cerrado. Planaltina, p. 1198, 2008. Disponível em: http://simposio.cpac.embrapa.br/simposio/ projeto/palestras/capitulo_32.pdf Acesso em: $10 \mathrm{dez} .2019$. 
SANTOS, C. F.; SIQUEIRA, E. S.; ARAÚJO, I. T.; MAIA, Z. M. G. A agroecologia como perspectiva de sustentabilidade na agricultura familiar. Revista Ambiente \& Sociedade, v.17, n.2, p. 33-52, 2014.

SILVA, J. A. Direito ambiental constitucional. 5 ed. São Paulo: Malheiros, 2004.

VINUTO, Juliana. Amostragem em bola de neve na pesquisa qualitativa: um debate em aberto. Revista Unicamp. Campinas, v. 22, n. 4, p. 203-220, ago./dez. 2014.

Submetido: $31 / 10 / 2019$

Aceito: $28 / 03 / 2020$ 


\title{
PERCEPÇÃO DE AGRICULTORES FAMILIARES SOBRE SUAS CONDIÇÕES DE SAÚDE E DO AMBIENTE
}

\begin{abstract}
Resumo
A agricultura é uma prática essencial para o desenvolvimento da sociedade e da manutenção da economia mundial. A agricultura familiar caracteriza-se pela utilização de mão-de-obra e gerenciamento familiar. A produção agrícola familiar é responsável por parte significativa da produção de alimentos no Brasil, que aporta para o abastecimento do mercado consumidor e contribui para a segurança alimentar e nutricional tanto dos consumidores como das famílias agricultoras. Objetivo: analisar a percepção de agricultores familiares sobre suas condições de saúde e as do ambiente. Metodologia: foram realizadas entrevistas com doze agricultores familiares de Seara, município do Oeste do estado de Santa Catarina. A análise dos resultados está apresentada de forma descritiva observando os núcleos temáticos manifestados nas entrevistas. Conclusão: os participantes do estudo produzem expressiva diversidade de alimentos e priorizam, para consumo próprio, alimentos oriundos da propriedade, livres de agrotóxicos. Os agricultores familiares têm clareza da necessidade e importância do cuidado com a terra e com o ambiente onde vivem, e compreendem que, para o ciclo da agricultura familiar dar certo, todo o ambiente deve ser respeitado, o que contribui para a promoção da saúde.

Palavras-chave: Agricultura Familiar. Produção de alimentos. Segurança alimentar e nutricional.
\end{abstract}




\title{
FAMILY FARMERS PERCEPTION OF THEIR HEALTH AND ENVIRONMENTAL CONDITIONS
}

\begin{abstract}
Introduction: Agriculture is an essential practice for the development of society and the maintenance of the world economy. Family farming is characterized by the use of labor and family management. Family agricultural production is responsible for a significant part of food production in Brazil, which contributes to supplying the consumer market and contributes to food and nutritional security for both consumers and farming families. Objective: to analyze the perception of family farmers about their health conditions and those of the environment. Methodology: interviews were conducted with twelve family farmers from Seara, a municipality in the west of the state of Santa Catarina. The analysis of the results is presented in a descriptive way, observing the thematic nuclei manifested in the interviews. Conclusion: the study participants produce a significant diversity of foods and prioritize, for their own consumption, food from the property, free of pesticides. Family farmers are clearly aware of the need and importance of caring for the land and the environment in which they live, and understand that, for the family farming cycle to work, the entire environment must be respected, which contributes to health promotion.
\end{abstract}

Keywords: Family Farming. Food production. Food and nutrition security. 